\title{
Influence of a constriction in the near field of the vocal folds: Physical modeling and experimental validation
}

\author{
Lucie Bailly \\ Département Parole et Cognition, GIPSA-lab, UMR5216 CNRS, INPG, UJF, Université Stendhal, 961 Rue \\ de la Houille Blanche, Domaine Universitaire, BP 46, 38402 Saint Martin d'Hères Cedex, \\ Laboratoire d'Acoustique de l' Université du Maine, UMR6613 CNRS, Université du Maine, Avenue Olivier \\ Messiaen, 72085 Le Mans Cedex 09, France \\ Xavier Pelorson, Nathalie Henrich, and Nicolas Ruty \\ Département Parole et Cognition, GIPSA-lab, UMR5216 CNRS, INPG, UJF, Université Stendhal, 961 Rue \\ de la Houille Blanche, Domaine Universitaire, BP 46, 38402 Saint Martin d'Hères Cedex, France
}

(Received 21 November 2007; revised 29 July 2008; accepted 30 July 2008)

\begin{abstract}
The involvement of the ventricular folds is often observed in human phonation and, in particular, in pathological and or some throat-singing phonation. This study aims to explore and model the possible aerodynamic interaction between the ventricular and vocal folds using suitable in vitro setups allowing steady and unsteady flow conditions. The two experimental setups consist of a rigid and a self-oscillating vocal-fold replica, coupled to a downstream rigid ventricular-fold replica in both cases. A theoretical flow modeling is proposed to quantify the aerodynamic impact of the ventricular folds on the pressure distribution and thereby on the vocal-fold vibrations. The mechanical behavior of the vocal folds is simulated by a distributed model accounting for this impact. The influence of the ventricular constriction is measured in both flow conditions and compared to the model outcome. This study objectively evaluates the additional pressure drop implied by the presence of a ventricular constriction in the larynx. It is demonstrated that such constriction can either facilitate or impede the glottal vibrations depending on the laryngeal geometrical configuration. The relevance of using static or dynamic vocal-fold replicas is discussed. () 2008 Acoustical Society of America. [DOI: 10.1121/1.2977740]
\end{abstract}

PACS number(s): 43.75.Rs, 43.70.Bk, 43.70.Jt [AL]

Pages: 3296-3308

\section{INTRODUCTION}

The ventricular folds, also called "false vocal folds", are two laryngeal structures located above the glottis and the laryngeal ventricle. They are not commonly involved during ordinary speech. Yet, their adduction has been observed in voice disorders such as ventricular dysphonia cases, where their interference in phonation may occur as a compensatory function (Nasri et al., 1996; Pinho et al., 1999). Although their physical properties (high viscosity and low stiffness) are different from those of biomechanical oscillators such as the vocal folds (Agarwal, 2004), their vibration has been observed during pathological (Nasri et al., 1996) and some throat-singing productions found in Asian culturesMongolian Kargyraa, Tibetan Dzo-ke chants (Fuks et al., 1998; Lindestad et al., 2001; Sakakibara et al., 2001, 2004)—and Mediterranean traditional polyphoniesSardinian Cantu A Tenore (Henrich et al., 2006).

The effects of the ventricular folds in phonation are still poorly understood. In vivo laryngeal examinations support the idea of a strong physical interaction between the ventricular and vocal folds (Fuks et al., 1998; Lindestad et al., 2001; Sakakibara et al., 2001; Bailly et al., 2007). Yet the physical nature of this interaction is unknown: is it related to an acoustical feedback, a mechanical conduction through the laryngeal mucosa, an aerodynamic drive,...? Few papers in the literature explore several hypotheses on the possible acoustic, mechanical, and/or aerodynamic effects underlying this interaction.

From an acoustical point of view, Fuks et al. (1998), Sakakibara et al. (2001, 2004), and Imagawa et al. (2003) studied the effect of including ventricular folds in the laryngeal tract using a two-mass model of the vocal folds. They showed how a supraglottal constriction contributes to regulate the voice quality specific to throat-singing techniques. Sakakibara et al. (2001) showed an increase in the acoustical power in the range of $1-3 \mathrm{kHz}$ in an inverse filtered spectrum of Kargyraa voices. Imagawa et al. (2003) evaluated the acoustical consequences of change in the area of the supraglottal structures. They showed that an increase in the laryngeal ventricle area moves the third and fourth formants $\left(F_{3}\right.$ and $\left.F_{4}\right)$ toward the second formant $F_{2}$ and sharpens it. A recent computational study suggested that the impingement of the glottal jet on the ventricular folds acts as a dipole source of sound adding high frequency components around $2-2.5 \mathrm{kHz}$, which are around the acoustic resonance frequency of the ventricle (Zhang et al., 2002). Hirschberg et al. (1996) also discussed this dipole sound generation, implying an enhancement of the radiation of the chaotic sound. The ventricular folds could induce a stable feedback oscillation of the glottal jet, which might result into whistling. The hypothesis of a mechanical transmission consistent with Rayleigh's theory of surface waves has been discussed by Tsai et al. (2004) in the case of the Sygyt phonation. The aerodynamical aspects of the vocal-ventricular interaction and, in 
particular, the impact of the ventricular folds on the laryngeal airflow have barely been investigated. Fuks et al. (1998) speculated that the driving of the ventricular folds could be a negative pressure generated by the airstream contained in the glottal pulse. They also measured higher oesophageal pressures when phonation switches from modal phonation to the vocal-ventricular mode. Yet, the following questions remain unanswered: What is the aerodynamic contribution of a downstream constriction near the vocal folds? How does such constriction affect glottal flow and pressure distribution inside the larynx? What does it induce on the vocal-fold self-oscillations?

Previous experimental investigations dealing with in vitro setups have provided an initial insight into the influence of the ventricular folds on the glottal airflow (Shadle et al., 1991; Pelorson et al., 1995; Agarwal, 2004; Bailly et al., 2006; Kucinschi et al., 2006). Using a rigid nonoscillating replica combining vocal folds and ventricular folds, Agarwal (2004) observed an increase or a decrease in the translaryngeal airflow resistance depending on the laryngeal geometry. The glottal jet curvature due to the Coanda effect typically observed through in vitro static replicas (Pelorson et al., 1994, 1995; Hirschberg et al., 1996; Hofmans, 1998; Hofmans et al., 2003; Scherer et al., 2001; Shinwari et al., 2003; Erath and Plesniak, 2006; Kucinschi et al., 2006) decreases with the presence of the ventricular folds (Shadle et al., 1991; Kucinschi et al., 2006). Flow visualization by Kucinschi et al. (2006) showed a downstream shift of the glottal separation point in the presence of the ventricular folds, inducing a conservation of the flow laminar properties over a longer distance. A significant pressure recovery associated with a reattachment of the jet flow is observed in Pelorson et al. (1995), in line with Miller et al. (1988). Therefore, to date, most studies have been conducted on in vitro rigid motionless replicas of the larynx from a (quasi-) steady point of view (Pelorson et al., 1995; Agarwal, 2004; Kucinschi et al., 2006).

In this paper, we present a theoretical and experimental work aiming at analyzing the fluid phenomena that may be induced by the presence of a constriction downstream and close to the vocal folds, similar to the ventricular folds. The parameter investigated is the aperture of the ventricular folds. First, simplified theoretical flow aspects accounting for this parameter are proposed in Sec. II. Then, their relevance is tested on suitable in vitro experimental devices described in Sec. III. Two different setups are designed to validate the theoretical outcome. The first one consists of two rigid and static vocal-fold and ventricular-fold replicas aligned; the second one relies on a deformable self-oscillating vocal-fold replica coupled to a downstream rigid and static ventricularfold replica of adjustable geometry. Within the scope of this study, the ventricular folds are thus explored under nonoscillatory conditions. Yet, we expect the results to provide relevant clues to study the physical contingency of ventricularfold self-sustained vibrations. Those replicas are not intended to reproduce a physiological reality but rather to test the proposed theoretical predictions. Finally in Sec. IV, theoretical flow predictions are compared to in vitro pressure measurements. The impact on the glottal vibrations is quantita-

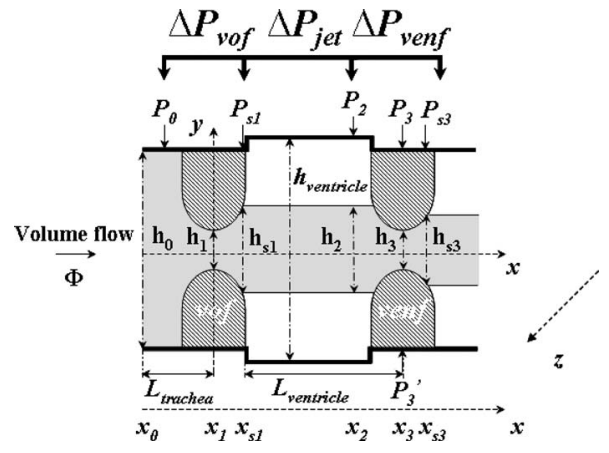

FIG. 1. Geometrical view of the laryngeal tube and relevant quantities of the aerodynamic study (vof: vocal folds; venf: ventricular folds).

tively evaluated on experimental data, and these results are compared with simulations using a two-mass model of the vocal folds accounting for the aerodynamic influence described in Sec. II.

\section{FLOW THEORY}

A geometrical representation of a simplified and schematic laryngeal tube is given in Fig. 1 along with all relevant parameters to model the aerodynamic jet behavior. The larynx is assumed to be symmetric with respect to the $x$ and $z$ axes. In the following, indices $i$ correspond to specific positions along the $x$ axis, as indicated in the figure. $h_{i}=h_{i}\left(x_{i}, t\right)$ and $A_{i}=W_{i} h_{i}$ respectively refer to the height and the crosssectional area of the channel flow at the position $x_{i}, W_{i}$ $=W\left(x_{i}\right)$ being the depth of the section along the $z$ direction. $h_{\text {vof }}$ (respectively $h_{\text {venf }}, h_{\text {ventricle }}$ ) corresponds to the aperture of the vocal folds (respectively the ventricular folds and the ventricle). Note that in this study, $h_{\text {vof }}$ always equals $h_{1}$, whereas $h_{\text {venf }}$ may differ from $h_{3}$. $h_{3}^{0}$ stands for a reference theoretical width of the flow in a no-ventricular-fold configuration. $P_{i}=P_{i}\left(x_{i}, t\right)$ represents the relative pressure predicted at $x_{i}$, as compared to the ambient atmospheric pressure.

The pressure distribution along the laryngeal tube is considered under the approximations of a laminar onedimensional incompressible flow, separating at $x_{s 1}$ and $x_{s 3}$. Three coupled subsystems are considered:

- the pressure drop across the vocal folds, $\Delta P_{\text {vof }}=P_{0}-P_{s 1}$,

- the emerging jet evolving in the ventricle, with a dissipation of kinetic energy $\Delta P_{\text {jet }}=P_{s 1}-P_{2}$, and

- the pressure drop across the ventricular folds, $\Delta P_{\text {venf }}=P_{2}$ $-P_{s 3}$.

The pressure $P_{s 3}$ is neglected, assuming a complete dissipation by turbulence downstream to the ventricular folds. Under these assumptions, the overall pressure drop $\Delta P$ governing the aerodynamics from the glottal inlet at $x_{0}$ to the flow separation at $x_{s 3}$ becomes

$$
\Delta P=\Delta P_{\text {vof }}+\Delta P_{\text {jet }}+\Delta P_{\text {venf }}=P_{0} .
$$

Equation (1) illustrates that the presence of a constriction in the flow channel can generate an additional pressure drop, $\Delta P_{\text {jet }}+\Delta P_{\text {venf }}=P_{s 1}$. The differences $\Delta P_{\text {jet }}$ and $\Delta P_{\text {venf }}$ are commonly set to zero in the case of no additional constriction (Ruty et al., 2007). If significant, this additional pressure 

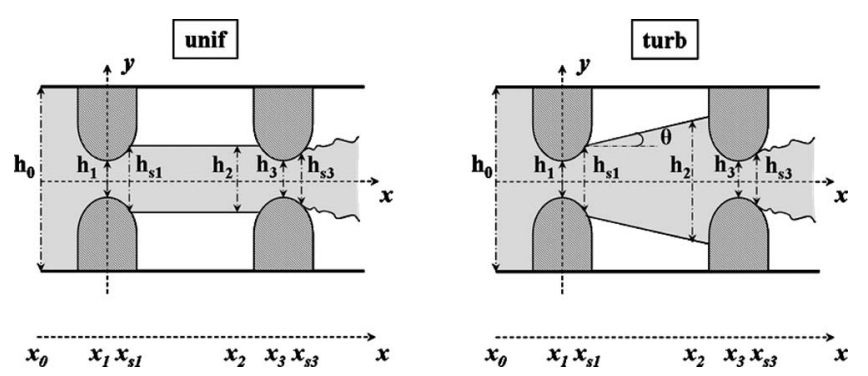

FIG. 2. Illustration of the hypotheses about the glottal jet expansion: (from left to right) uniform jet (unif); turbulent jet with $\delta \sim x$ and $\theta=4^{\circ}$ (turb), $\delta$ referred to as the glottal jet width.

drop is likely to alter the volume flow velocity, $\Phi$, and produce a pressure recovery downstream the glottis. The theories detailed further below are an attempt to predict this pressure recovery using $P_{0}$ and $h_{1}$ as inputs to estimate consecutively $A_{s 1}, A_{s 3}, A_{2}, \Phi, P_{s 1}, P_{2}, P_{3}$, and $P_{3}^{\prime}$ (see Fig. 1 ). They combine a separation model predicting $A_{s 1}$ and $A_{s 3}$, a jet-flow geometrical model predicting $A_{2}$, and an aerodynamic model predicting $\Phi, P_{s 1}, P_{2}, P_{3}$, and $P_{3}{ }^{\prime}$.

\section{A. Calculation of $\Delta P_{\text {vof }}$}

The estimation of the pressure drop on the inlet of the glottis $\Delta P_{\mathrm{vof}}=P_{0}-P_{s 1}$ derives from the Euler equations governing the dynamics of inviscid flows coupled to a separation model. The expansion of the vocal folds to its downstream end causes the flow to separate from the wall at $x_{s 1}$. For the sake of simplicity, a semiempirical model based on Liljencrants' ad hoc criterion is used as an alternative to a boundary-layer separation theory: $A_{s 1}=1.2 \times A_{1}$ (Ruty et al., 2007). Neglecting the effects of wall vibrations and the volume airflow variations in time, the volume flow velocity $\Phi$ is constant, and it can be deduced from the overall pressure loss $\Delta P$. Combining these assumptions with steady Bernoulli's equation applied between $x_{0}$ and $x_{s 1}$ yields to

$$
\Delta P_{\mathrm{vof}}=P_{0}-P_{s 1}=\frac{1}{2} \rho \Phi^{2}\left(\frac{1}{A_{s 1}^{2}}-\frac{1}{A_{0}^{2}}\right),
$$

where $\rho$ is the air density.

\section{B. Calculation of $\Delta P_{\text {jet }}$}

Two different jet flows are considered in the larynx: the jet downstream to the glottis and the jet downstream to the ventricular folds. Past the ventricular folds, the kinetic energy of the separated flow is assumed to be fully dissipated by turbulence (no reattachment), which theoretically comes to $P_{s 3}=0$. Understanding how the jet evolves from glottal separation to the ventricular inlet is crucial in order to predict accurately the pressure distribution along the channel.

Two hypotheses are formulated regarding the geometrical expansion of the glottal jet. Each of them is illustrated in Fig. 2.

- Hypothesis "unif" assumes a "uniform jet" without any expansion:

$$
A_{2}=h_{2} W_{2}=h_{s 1} W_{2} \text {. }
$$

- Hypothesis "turb," the so-called "turbulent jet" hypothesis, derives from a self-similar assumption of a free turbulent plane jet. A dimensional analysis leads to a linear growth of the jet width, $\delta$, with increasing downstream distance regardless of the Reynolds number. Kundu (1990) reported from experimental data that a turbulent plane jet grows at a half-angle of $4^{\circ} . A_{2}$ calculation is then represented as follows:

$$
A_{2}=\left[h_{s 1}+2 \tan 4^{\circ}\left(x_{2}-x_{s 1}\right)\right] W_{2} .
$$

Whatever the jet-flow expansion theory adopted, the dissipation $\Delta P_{\text {jet }}$ due to flow enlargement is either neglected (Hyp.a) or modeled by a quasisteady-pressure recovery determined from Eq. (5) (Hyp.b), in line with the estimations based on momentum considerations and the equation for diffuser flow suggested in Ishizaka and Flanagan (1972). This equation derives from the macroscopic mass and momentum conservation laws applied to the flow-detachment section $A_{s 1}$ and to section $A_{2}$ under the assumption that the pressure on section $A_{2}-A_{s 1}$ equals $P_{s 1}$ according to experimental observations (Ishizaka and Matsudaira, 1972; Blevins, 1992),

$$
\Delta P_{\mathrm{jet}}=-\frac{\rho}{2} \frac{\Phi^{2}}{A_{s 1}^{2}}\left[2 \frac{A_{s 1}}{A_{2}}\left(1-\frac{A_{s 1}}{A_{2}}\right)\right] .
$$

\section{Calculation of $\Delta \boldsymbol{P}_{\text {venf }}$}

The calculation of $\Delta P_{\text {venf }}=P_{2}$ is similar to the one of $\Delta P_{\text {vof }}$. The divergent part of the ventricular folds decelerates the flow until separation at $x_{s 3}$, determined by means of Liljencrants' semiempirical model. $\Delta P_{\text {venf }}$ is then estimated, thanks to the Bernoulli equation applied between $x_{2}$ and $x_{s 3}$. The aerodynamical impact of the ventricular folds is only considered when the ventricular aperture $h_{\text {venf }}$ drops below a critical height, $h_{3}^{0}$. This transition gap is estimated as the height of the channel flow, which would be theoretically expected at $x_{3}$ in the case without any ventricular constriction. If $h_{\text {venf }}$ exceeds this aperture, it is then assumed that the presence of the ventricular folds does not alter the glottal jet, and therefore $\Delta P_{\text {venf }}$ is neglected,

$$
\begin{aligned}
& \Delta P_{\text {venf }}=P_{2}=\frac{1}{2} \rho \Phi^{2}\left(\frac{1}{A_{s 3}^{2}}-\frac{1}{A_{2}^{2}}\right) \text { if } h_{\text {venf }}<h_{3}^{0}, \\
& \Delta P_{\text {venf }}=P_{2}=0 \text { if } h_{\text {venf }} \geqslant h_{3}^{0} .
\end{aligned}
$$

Three assumptions on flow are also considered. A potential quasisteady flow described by Eqs. (2) and (6) (Hyp.1), a viscous quasisteady flow (Hyp.2), and a potential unsteady flow (Hyp.3) are hypothesized. Equations (2) and (6) are modified to account for viscous flow effects (Hyp.2), whose contribution is no longer negligible for small constriction heights. The extra pressure loss induced by fluid viscosity is expressed by a Poiseuille correction reading

$$
12 \mu \int_{x_{0}}^{x_{s 1}} \frac{\Phi(t)}{A^{3}(x, t)} d x
$$

in Eq. (2) and 


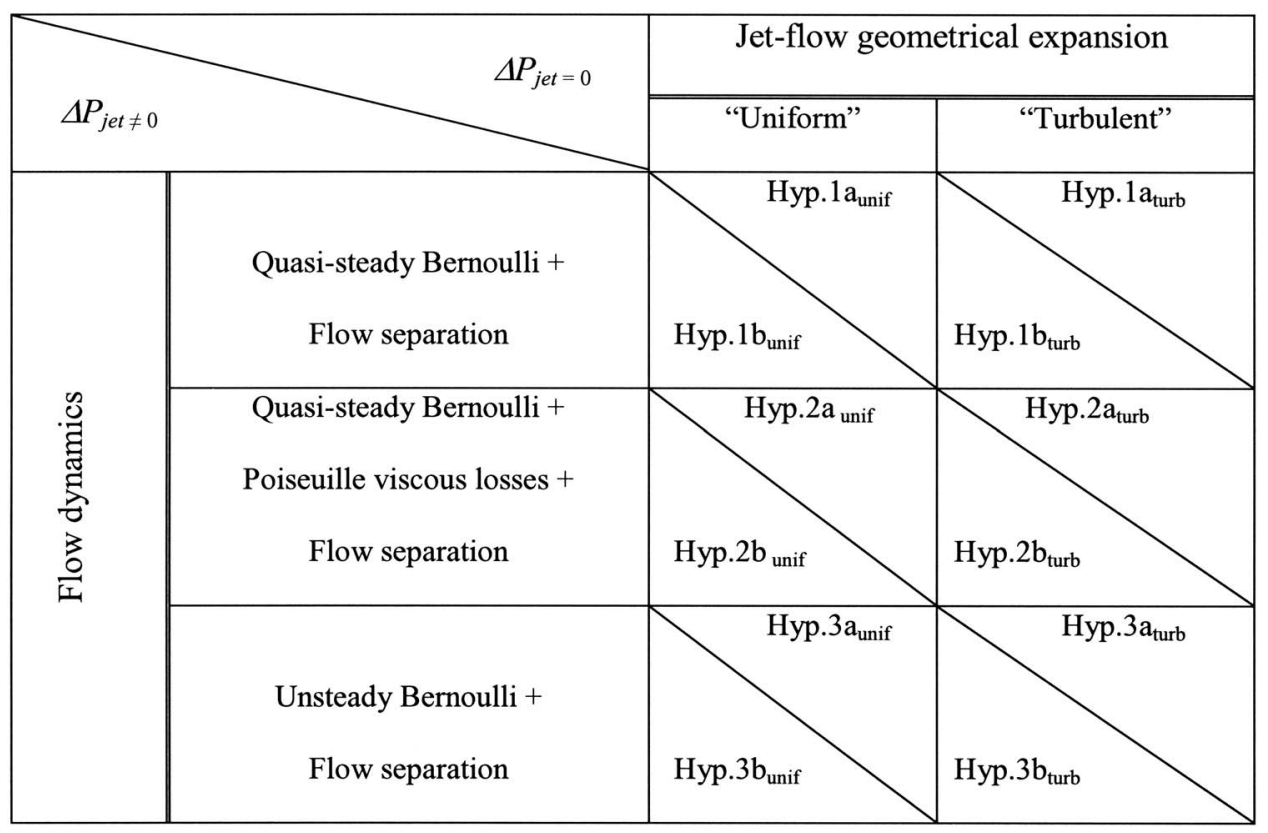

$$
12 \mu \int_{x_{2}}^{x_{s 3}} \frac{\Phi(t)}{A^{3}(x, t)} d x
$$

in Eq. (6), where $\mu$ is the air dynamic viscosity. Under Hyp.3, $\Delta P_{\text {vof }}$ and $\Delta P_{\text {venf }}$ are equal to the Bernoulli pressure corrected for flow unsteadiness due to air inertia. The additional term in the estimation of $\Delta P_{\text {vof }}$ and $\Delta P_{\text {venf }}$ reads

$$
\rho \int_{x_{0}}^{x_{s 1}} \frac{\partial}{\partial t} \frac{\Phi(t)}{A(x, t)} d x
$$

and

$$
\rho \int_{x_{2}}^{x_{s 3}} \frac{\partial}{\partial t} \frac{\Phi(t)}{A(x, t)} d x
$$

respectively. Table I summarizes the different theories introduced.

Combining $\Delta P_{\mathrm{vof}}, \Delta P_{\text {jet}}$, and $\Delta P_{\mathrm{venf}}$, one can predict the instantaneous pressure within the larynx. Under (Hyp. $\left.1 \mathrm{a}_{\text {unif }}\right)$ assumption, for instance, the volume airflow can be analytically calculated and the system $\{(2)$ and (6) $\}$ provides the following predictions for $P_{2}$ and $P_{3}$ :

$$
\begin{aligned}
& \frac{P_{2}}{P_{0}}=\frac{\left(A_{s 1}^{2}-A_{s 3}^{2}\right)}{\left(A_{0}^{2}-A_{s 3}^{2}\right)} \frac{A_{0}^{2}}{A_{s 1}^{2}} \quad \text { if } h_{\mathrm{venf}}<h_{3}^{0}, \\
& \frac{P_{2}}{P_{0}}=0 \quad \text { if } h_{\mathrm{venf}} \geqslant h_{3}^{0} \quad\left(\text { with } h_{3}^{0}=h_{s 1}\right), \\
& \frac{P_{3}}{P_{2}}=-0.44 \frac{A_{1}^{2}}{A_{1}^{2}-A_{3}^{2}} \quad \text { if } h_{\mathrm{venf}}<h_{3}^{0},
\end{aligned}
$$

$$
\frac{P_{3}}{P_{2}} \text { not defined if } \quad h_{\mathrm{venf}} \geqslant h_{3}^{0} .
$$

The turbulent jet assumption (Hyp. $1 \mathrm{a}_{\text {turb }}$ ) allows us to express the pressure recovery by geometrical ratios as well,

$$
\begin{aligned}
& \frac{P_{2}}{P_{0}}=\frac{1}{1+\frac{A_{s 3}^{2} A_{2}^{2}\left(A_{0}^{2}-A_{s 1}^{2}\right)}{A_{0}^{2} A_{s 1}^{2}\left(A_{2}^{2}-A_{s 3}^{2}\right)}} \text { if } h_{\mathrm{venf}}<h_{3}^{0}, \\
& \frac{P_{2}}{P_{0}}=0 \text { if } h_{\mathrm{venf}} \geqslant h_{3}^{0} .
\end{aligned}
$$

Alternatively, Agarwal (2004) proposed the use of another parameter, $R$, defined as

$$
R=\frac{P_{0}-P_{s 3}}{\Phi_{\text {venf }}} \frac{\Phi_{\text {vof }}}{P_{0}-P_{s 3}}=\frac{\Phi_{\text {vof }}}{\Phi_{\text {venf }}},
$$

where $\Phi_{\text {vof }}$ refers to the base volume airflow calculated without ventricular folds in the larynx and $\Phi_{\text {venf }}$ refers to the volume airflow estimated in the presence of ventricular folds. Figure 3 presents two theoretical predictions of $R$ as a function of $h_{\mathrm{venf}} / h_{\mathrm{vof}}$, deriving from the assumptions previously mentioned (Hyp. $1 \mathrm{a}_{\text {turb }}$ and Hyp. $1 \mathrm{a}_{\text {unif }}$ ). In each case, Eq. (10) leads to

$$
\begin{aligned}
& R=\sqrt{\frac{\frac{1}{A_{s 3}^{2}}-\frac{1}{A_{0}^{2}}+\frac{1}{A_{s 1}^{2}}-\frac{1}{A_{2}^{2}}}{\frac{1}{A_{s 1}^{2}}-\frac{1}{A_{0}^{2}}}} \text { if } h_{\mathrm{venf}}<h_{3}^{0}, \\
& R=1 \text { if } h_{\mathrm{venf}} \geqslant h_{3}^{0} .
\end{aligned}
$$

Figure 3 presents the nonlinear relationship between $R$ and $h_{\mathrm{venf}} / h_{\mathrm{vof}}$ for $L_{\mathrm{ventricle}}=26 \mathrm{~mm}, h_{\mathrm{vof}}=2.90 \mathrm{~mm}$, and $P_{0}$ 


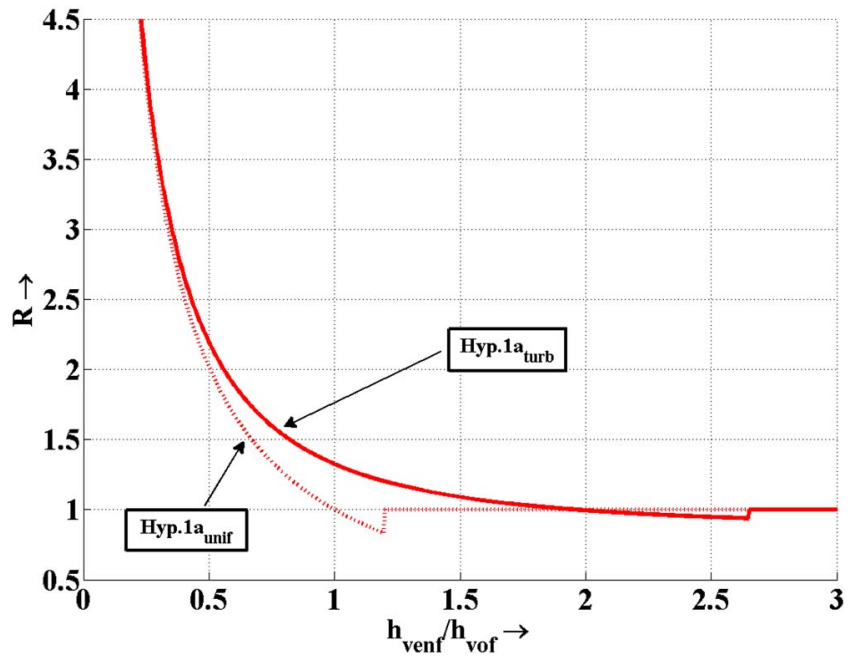

FIG. 3. (Color online) Theoretical predictions of the translaryngeal airflow resistance $R=\Phi_{\mathrm{vof}} / \Phi_{\mathrm{venf}}$ against $h_{\mathrm{venf}} / h_{\mathrm{vof}}$ under two flow assumptions: Hyp. $1 \mathrm{a}_{\text {unif }}$ (dotted line) and Hyp. $1 \mathrm{a}_{\text {turb }}$ (solid line).

$=500 \mathrm{~Pa}$. It is interesting to note that these predictions qualitatively explain the experimental data presented by Agarwal (2004). More precisely $R$ appears as a decreasing function of $h_{\mathrm{venf}} / h_{\mathrm{vof}}$ and tends toward an asymptotic value of 1 . Moreover, for a small region of $h_{\mathrm{venf}} / h_{\mathrm{vof}}, R$ can become smaller than unity. This result is also in line with Kucinschi et al. (2006), who showed by means of flow visualization that the presence of the ventricular folds can accelerate and straighten the glottal jet [as previously observed by Shadle et al. (1991)], thus creating less energy dissipation.

\section{MATERIAL AND METHOD}

As an attempt to validate the above mentioned theoretical expectations, different experimental setups are designed, allowing steady or unsteady in vitro flow conditions.

\section{A. Description of the laryngeal geometry 1. Anatomical dimensions}

Tomographic anatomical observations approximate the gap separating the ventricular folds $h_{\mathrm{venf}}$ ranging from 2.3 to $8.3 \mathrm{~mm}$ (mean value of $6.1 \mathrm{~mm}$ ) for male subjects phonating an /a/ in laryngeal mechanisms $M_{1}$ (equivalent to "modal" laryngeal register) and $M_{2}$ (equivalent to a "falsetto" laryngeal register) (Henrich, 2006; Roubeau et al., 2007) and ranging from 4.0 to $6.8 \mathrm{~mm}$ (mean value of $5.5 \mathrm{~mm}$ ) for male singers performing an /a/ (Hollien and Colton, 1969; Wilson, 1976; Agarwal, 2004; Agarwal et al., 2003). The average distance from the superior-medial surfaces of the vocal folds to the minimum constriction height of the ventricular folds, $L_{\text {ventricle }}$ (see Fig. 1), reportedly ranges from 3.7 to $7.5 \mathrm{~mm}$ (mean value of $5.3 \mathrm{~mm}$ ) for speakers and ranges from 3.3 to $6.1 \mathrm{~mm}$ (mean value of $4.6 \mathrm{~mm}$ ) for singers. The ventricle height $h_{\text {ventricle }}$ (see Fig. 1) is in the range of $9.6-23.0 \mathrm{~mm}$ (mean value of $16.0 \mathrm{~mm}$ ) for male speakers and $10.8-15.6 \mathrm{~mm}$ (mean value of $13.9 \mathrm{~mm}$ ) for male singers. Those physiological data are provided in Table II.

\section{Description of the laryngeal replicas}

The static experimental setup consists of a 3:1 upscaled simplified replica of the human larynx. The laryngeal replica consists first of a rigid 25-mm-thick vocal-fold replica having a rounded shape (radius of curvature of $6 \mathrm{~mm}$ ). The vocal-fold replica is coupled to a rigid 25-mm-thick ventricular-fold replica having a rounded shape (radius of curvature of $5 \mathrm{~mm}$ ). The coupling between the vocal and the ventricular folds defines a ventricle having a circular crosssection of a constant diameter $\left(h_{\text {ventricle }}=26 \mathrm{~mm}\right)$. The distance $L_{\text {trachea }}$ separating the glottal constriction to the pressure reservoir is $258 \mathrm{~mm}$. The glottal aperture $h_{\mathrm{vof}}$, as well as the ventricular aperture $h_{\text {venf }}$, can be controlled parametrically with an accuracy of $\pm 0.05 \mathrm{~mm}$.

Except when mentioned, $L_{\text {ventricle }}$ is chosen as $26 \mathrm{~mm}$, which is the closest distance allowed by the setup.

TABLE II. Comparative table: physiological characteristics of a male adult voice in speech and singing phonation [typical data obtained from Hollien and Colton (1969), Wilson (1976), Hirano et al. (1983), Agarwal (2004), Agarwal et al. (2003), and Bailly et al. (2007)] against geometrical and dynamical characteristics of the laryngeal replica.

\begin{tabular}{lcc}
\hline \hline & In vivo data & In vitro data \\
\hline Scale & 1 & 3 \\
Glottal length, $d$, mean value (along the $x$ direction) & $4 \mathrm{~mm}$ & $9 \mathrm{~mm}, 12 \mathrm{~mm}^{\mathrm{a}}$ \\
Glottal gap, $h_{\text {vof }}$, range of values & $0-1.02 \mathrm{~mm}$ & $0-5.95 \mathrm{~mm}$ \\
Ventricular gap, $h_{\text {venf }}$, range of values & $0-9.0 \mathrm{~mm}$ & $0.04-26 \mathrm{~mm}$ \\
Ventricle length, $L_{\text {ventricle }}$, range of values & $3.3-7.5 \mathrm{~mm}$ & $26-181 \mathrm{~mm}$ \\
Ventricle height, $h_{\text {ventricle }}$ range of values & $9.6-23.0 \mathrm{~mm}$ & $26 \mathrm{~mm}$ \\
Aspect ratio, $h_{\text {venf }} / L_{\text {ventricle }}$, range of values & $0-2.7$ & $0-1$ \\
Alimentation pressure, $P_{0}$, range of values & $300-1000 \mathrm{~Pa}$ & $100-2000 \mathrm{~Pa}$ \\
Reynolds number, Re, range of values & $1700-3300^{\mathrm{b}}$ & $1000-4600^{\mathrm{b}}$ \\
Strouhal number, Sr, range of values & $0.01-0.03^{\mathrm{b}}$ & $0.02-0.1^{\mathrm{b}}$ \\
\hline \hline
\end{tabular}

${ }^{\mathrm{a}} 9 \mathrm{~mm}$ for the dynamical laryngeal replica, $12 \mathrm{~mm}$ for the static laryngeal replica.

${ }^{\mathrm{b}}$ Estimated from alimentation pressure, glottal gap, $h_{\mathrm{vof}}=1 \mathrm{~mm}$ (mean value), and frequency of oscillations, $F_{0}=150 \mathrm{~Hz}$ (mean value). 


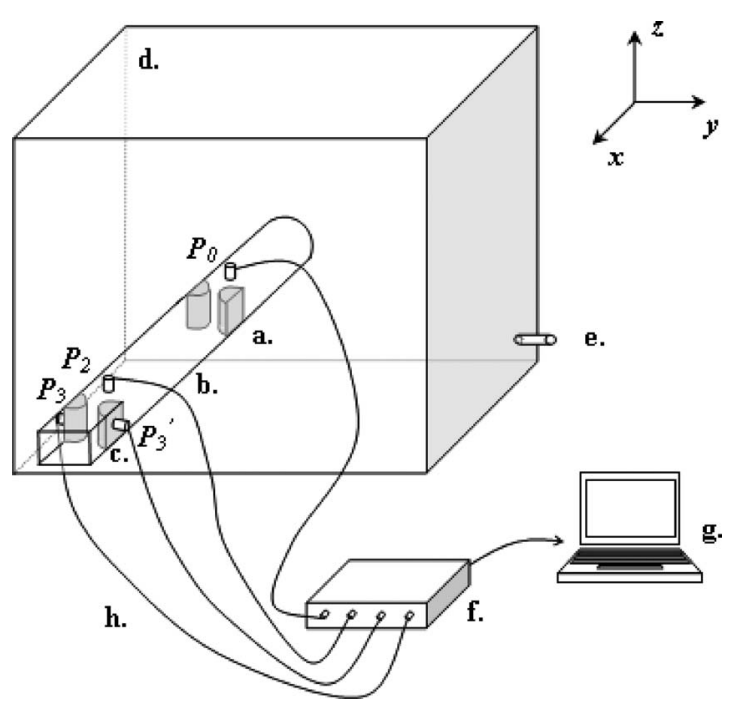

FIG. 4. Sketch of the flow facility and experimental setup using the static laryngeal replica (not to scale). (a) Static replica of the vocal folds, (b) cylindrical replica of the laryngeal ventricle, (c) static replica of the ventricular folds, (d) pressure reservoir (lungs), (e) air admission, (f) signal conditioner, (g) PC, and (h) pressure sensors.

In order to realize unsteady flow conditions, another experimental setup has been used. It consists of a 20-mm-thick replica of the vocal folds made of rubber filled with water under pressure. For a sufficient alimentation pressure $P_{0}$, the vocal-fold replica can be driven into self-sustained oscillations. Alimentation pressures, vibration amplitude, and oscillation frequencies are comparable with human phonation. Details of this setup can be found in Ruty et al. (2006).

The pressure of the water inside the self-oscillating replica is chosen as $5000 \mathrm{~Pa}$. This corresponds to an optimal oscillatory behavior as observed in Ruty et al. (2007). Under this configuration, the glottal longitudinal length, $d$, is $9 \mathrm{~mm}$ in the dynamical replica.

The ventricular folds and ventricle replicas are identical to those used in the static configuration. In order to avoid strong acoustical coupling with the downstream elements (Zhang et al., 2006), the inlet length $L_{\text {trachea }}$ is reduced to $119 \mathrm{~mm}$. This induces a first quarter-wave acoustical resonance at about $714 \mathrm{~Hz}$, which is much higher than the fundamental frequency of the airflow oscillations that does not exceed $200 \mathrm{~Hz}$.

The correspondence between in vivo data and in vitro data allowed by our device is detailed in Table II. Dynamic similarity is preserved by relevant dimensionless Reynolds $\left(\operatorname{Re}=U_{1} h_{\mathrm{vof}} / v\right)$ and Strouhal $\left(\mathrm{Sr}=F_{0} d / U_{1}\right)$ numbers, where the characteristic mean flow velocity $U_{1}$ is approximated by $U_{1}=\sqrt{2 \Delta P_{\text {vof }} / \rho}, v$ is the air kinematic viscosity, and $F_{0}$ is the mean oscillation fundamental frequency.

\section{B. Experimental procedure on the static laryngeal replica}

The experimental setup is illustrated in Fig. 4. A pressure reservoir supplies the setup. The dynamic pressures upstream, $P_{0}$, within the jet, $P_{2}$, and within the ventricular-fold

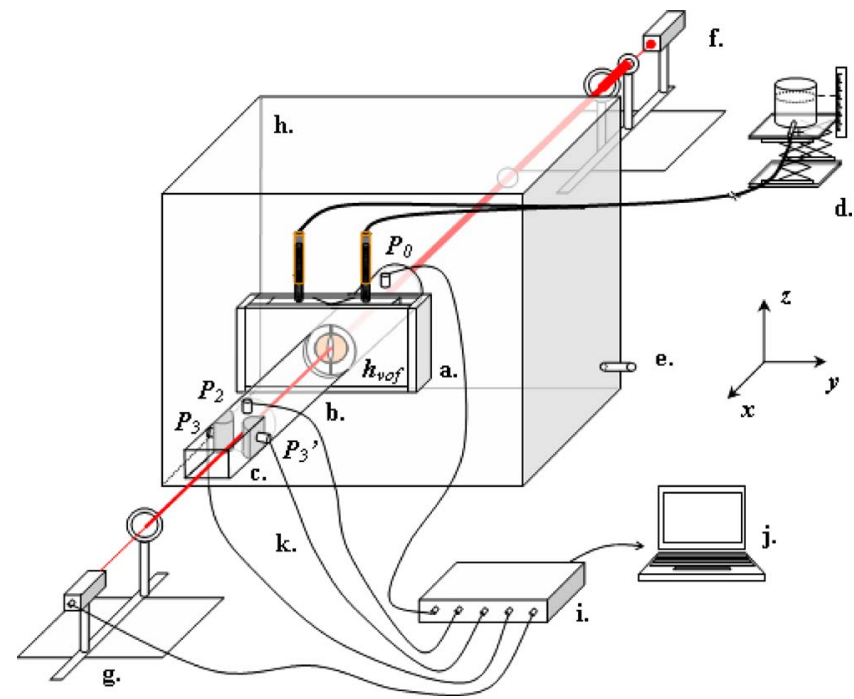

FIG. 5. (Color online) Sketch of the flow facility, the optical device, and the experimental setup using the dynamical laryngeal replica (not to scale). (a) Dynamical replica of the vocal folds, (b) cylindrical replica of the laryngeal ventricle, (c) static replica of the ventricular folds, (d) water pressure reservoir, (e) air admission, [(f) and (g)] laser diode, optical lenses, and photo sensor, (h) pressure reservoir (lungs), (i) signal conditioner, (j) PC, and (k) pressure sensors.

replica, $P_{3}$, are measured using Kulite (XCS-0.93-0.35Bar-G) or Endevco (8507C) pressure sensors supplied by a Labor-Netzgerat power supply (EA-3005S).

The pressure sensor measuring $P_{0}$ is located $24 \mathrm{~mm}$ upstream of the vocal-fold replica. The sensor measuring $P_{2}$ is set $3 \mathrm{~mm}$ upstream of the ventricular-fold replica. $P_{3}$ is measured at the minimum constriction position within the ventricular-fold replica. An additional pressure sensor $P_{3}{ }^{\prime}$ was also added to check for an asymmetry of the flow.

All pressure sensors are calibrated against an electronical manometer (Aschcroft XLdp) with typical accuracy of $\pm 5 \mathrm{~Pa}$. Electrical signals are postprocessed using a preamplifier/conditioning board (National Instruments SXCI-1121) connected to a PC through a National Instruments BNC-2080 card and a National Instruments PCI-MIO$16 \mathrm{XE}$ acquisition card. The acquired data are processed using the Labview7 software (National Instruments). The sampling frequency for all acquisitions is $10 \mathrm{kHz}$. The pressure measurements are repeated several times for each geometrical configuration. The pressure signal is smoothed using a low-pass Butterworth filter (20 Hz cutoff frequency).

The variable apertures of both the vocal-fold and the ventricular-fold replica were measured using calibrated plates with an accuracy of $0.05 \mathrm{~mm} . P_{0}$ is controlled and maintained constant thanks to the manometer mentioned above.

\section{Experimental procedure on the dynamical laryngeal replica}

\section{Pressure and geometrical dynamics measurement}

The unsteady dynamical experimental setup is illustrated in Fig. 5. The pressure sensor measuring $P_{0}$ is located $35 \mathrm{~mm}$ upstream of the vocal-fold replica, whereas the other pressure sensors were located as previously. 


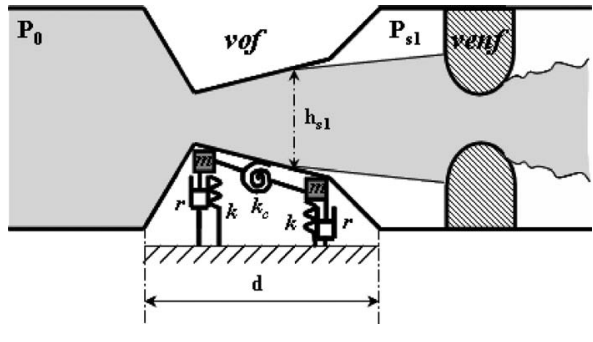

FIG. 6. Sketch of the two-mass model of the vocal folds combined to the theoretical flow description of the ventricular-fold influence under Hyp. $1 \mathrm{a}_{\text {turb. }}$.

During an experimental round, the upstream pressure $P_{0}$ is continuously increased until self-sustained oscillations of the vocal-fold replica appear. An optical system consisting of a laser diode (P. Fontaine dc amplifier FTN2515 supply) aligned with a photosensor (BPW34, Solartron dc power supply) allows us to quantify the vocal-fold replica opening during oscillation. The optical system does not measure the opening area but the minimum glottal aperture at the midwidth of the vocal-fold replica along the flow direction, $h_{\mathrm{vof}}$. Details of this setup can be found in Ruty et al. (2007). Typical accuracy for the measure of $h_{\mathrm{vof}}$ is $\pm 0.01 \mathrm{~mm}$.

The mechanical response of the deformable replica is obtained using a pressure driver unit (ERSTU-100) added in the vicinity of the vocal-fold replica. It provides a sinusoidal excitation whose frequency varies from 45 to $500 \mathrm{~Hz}$ in steps of $1 \mathrm{~Hz}$. The opening $h_{\text {vof }}$ for each acoustical excitation is captured by means of the optical device previously detailed. Mechanical resonance frequencies, quality factors, and equilibrium positions are then extracted (Ruty et al., 2007). From these parameters mechanical constants for the theoretical models can be easily inferred.

The experimental phonation onset pressure $P_{\text {onset }}$ represents the minimum upstream pressure necessary to sustain the vocal-fold replica oscillations. The upstream pressure for which oscillations disappear in a decreasing-flow sweep corresponds to the phonation offset pressure $P_{\text {offset }}$. Both pressures are measured from the recorded pressure signal $P_{0}$, modulated by the oscillation, using a periodicity detection method. The fundamental frequency of vocal-fold replica oscillation is also extracted from the measurements via a $0.05 \mathrm{~s}$ windowing. The periodicity detection method is based on autocorrelation and peak detection techniques classically used in voice signal processing (Henrich et al., 2004).

\section{Simulation of the vocal-fold dynamics using a two- mass model}

In order to analyze the experimental data with the selfoscillating vocal-fold replica, a theoretical model for the selfsustained oscillations is needed. For the sake of simplicity, a reduced "two-mass" mechanical model is used (Lous et al., 1998), as shown in Fig. 6. It is controlled by a set of mechanical input parameters: the mass $(m)$, stiffness $\left(k, k_{c}\right)$, and damping $(r)$. These parameters are directly deduced from the mechanical response of the deformable replica.

The aerodynamical contribution of the ventricular folds downstream of the glottis is accounted for by considering the

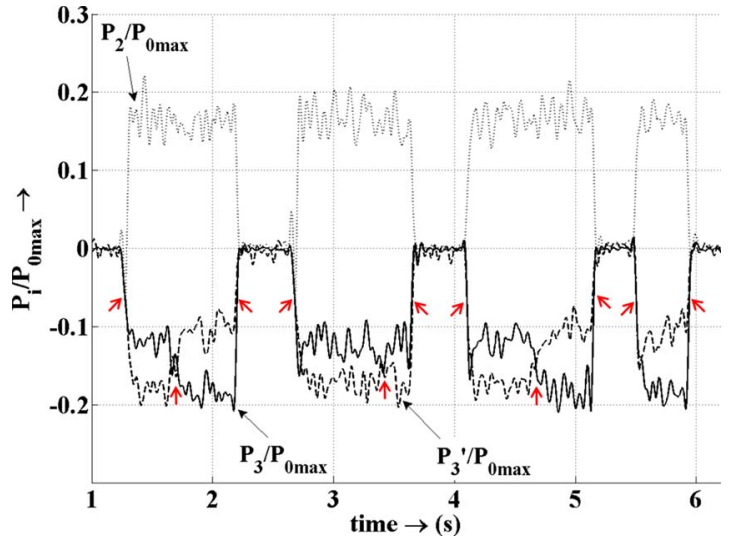

FIG. 7. (Color online) Experimental normalized pressures $P_{2} / P_{0 \text { max }}$ (dotted line), $P_{3} / P_{0 \max }$ (solid line), and $P_{3}{ }^{\prime} / P_{0 \max }$ (dashed line) as functions of time acquired on the static laryngeal replica. Four repetitions of a measurement with $L_{\text {ventricle }}=31.5 \mathrm{~mm}, h_{\mathrm{vof}}=3.25 \mathrm{~mm}$, and $h_{\mathrm{venf}}=5.95 \mathrm{~mm}$, i.e., $h_{\text {venf }} / h_{\text {vof }} \sim 1.8$ and $P_{0 \max }=109 \mathrm{~Pa}$. In the case of the first and third repetitions, note the changing asymmetry of the flow at the level of the ventricular-fold constriction. Small arrows indicate time sequences for which $P_{3} / P_{0 \text { max }}$ and $P_{3}{ }^{\prime} / P_{0 \text { max }}$ are close.

pressure past the flow separation point that does not equal the atmospheric pressure, i.e., $P_{s 1} \neq 0 . P_{s 1}$ is predicted using the theoretical expectation detailed in Sec. II. The onset subglottal pressure and the fundamental frequency of oscillation are predicted by applying a linear stability analysis to the mechanical model (Van Hirtum et al., 2007; Ruty et al., 2007).

\section{RESULTS AND DISCUSSION}

In this section, we will compare the predictions of the theoretical models and the experimental data. First, the influence of the ventricular folds on the glottal flow and on the pressure distribution in the larynx is considered. A second important feature is the phonation threshold pressures and the fundamental frequency. In principle, up to 12 theoretical expectations have been tested systematically. However, for the sake of clarity, only a few typical illustrative predictions will be presented.

\section{A. Static laryngeal replica \\ 1. Experimental observations}

Figure 7 presents a typical example of the experimental data acquired on the static laryngeal replica. The parameters used are $L_{\mathrm{ventricle}}=31.5 \mathrm{~mm}$ and $h_{\mathrm{venf}} / h_{\mathrm{vof}} \sim 1.8$. In this example, the upstream alimentation pressure $P_{0}$ is increased from $0 \mathrm{~Pa}$ to a permanent flow threshold maintained at around $100 \mathrm{~Pa}$. The measurement is repeated four times under the same experimental conditions. $P_{2}, P_{3}$, and $P_{3}{ }^{\prime}$ are normalized by the average threshold $P_{0 \text { max }}$ and are displayed as functions of time. As preliminary observations, a pressure recovery is noticeably evidenced: $P_{2}$ increases to about $20 \%$ of the alimentation pressure $P_{0}$. The pressures measured for $P_{3}$ and $P_{3}{ }^{\prime}$ are negative, which is likely to correspond to a Bernoulli effect. An interesting feature can be highlighted: $P_{3}$ and $P_{3}{ }^{\prime}$ variations reveal a flow instability within the ventricular-fold replica for a stationary glottal flow (as indicated by stationary values of $P_{0}$ and $P_{2}$ ). These discrepancies 


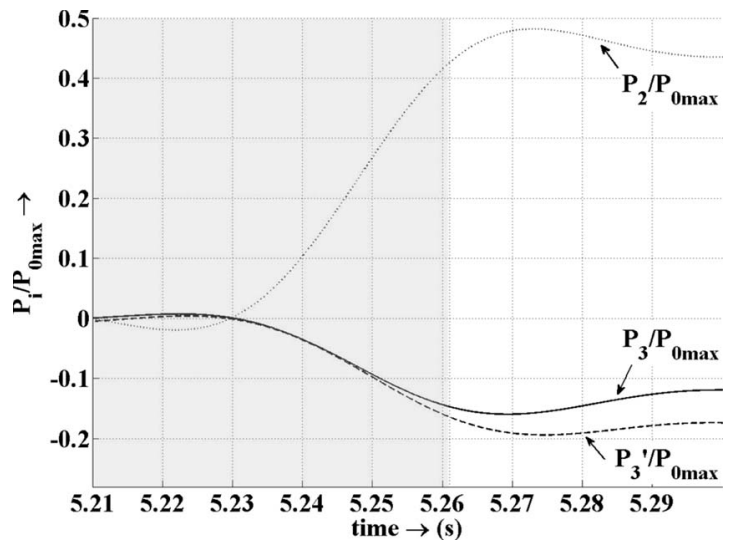

FIG. 8. Experimental normalized pressures $P_{2} / P_{0 \max }$ (dotted line), $P_{3} / P_{0 \max }$ (solid line), and $P_{3}{ }^{\prime} / P_{0 \max }$ (dashed line) as functions of time acquired on the static laryngeal replica. $L_{\mathrm{ventricle}}=31.5 \mathrm{~mm}, h_{\mathrm{vof}}=3.25 \mathrm{~mm}$, and $h_{\text {venf }}=3.10 \mathrm{~mm}$, i.e., $h_{\text {venf }} / h_{\text {vof }} \sim 0.9$ and $P_{0 \text { max }}=296 \mathrm{~Pa}$.

can be understood as the result of a Coanda effect, which induces a skewing of the jet flow to one or the other side of the ventricular-fold replica (Pelorson et al., 1995; Kucinschi et al., 2006). As a matter of fact, the measured $P_{3} / P_{0 \text { max }}$ and $P_{3}{ }^{\prime} / P_{0 \text { max }}$ reveal not only an asymmetrical flow but also that the asymmetry can change from one side to the other. The dynamical aspect of the jet skewing is thus evidenced, consistently with Kucinschi et al. (2006), who also observed a jet downstream to the ventricular folds "bistable" in direction for a narrow geometrical configuration $h_{\mathrm{venf}} / h_{\mathrm{vof}}$.

Figure 8 displays time dependent pressure measurements performed for a smaller ventricular gap $\left(h_{\text {venf }} / h_{\text {vof }}\right.$ 0.9). $P_{0}$ is increased from $0 \mathrm{~Pa}$ up to a steady-pressure value of $296 \mathrm{~Pa}$. Experimental data exhibit a significant pressure recovery $\left(P_{2} \alpha 46 \%\right.$ of $\left.P_{0}\right)$, as well as a Coanda effect at the ventricular-fold replica. Note that for $P_{0}$ below around $273 \mathrm{~Pa}$ (see the gray area in Fig. 8), $P_{3} / P_{0 \text { max }}$ and $P_{3}{ }^{\prime} / P_{0 \text { max }}$ are identical with respect to the measurement accuracy $( \pm 5 \mathrm{~Pa})$, suggesting a time sequence where the glottal jet expands symmetrically before the Coanda phenomenon is established. This result is another dynamical feature of the Coanda effect. In particular, our results support the work by Pelorson et al. (1994), Hirschberg et al. (1996), Hofmans (1998), and Hofmans et al. (2003), who suggested that the Coanda effect is not important during a transient and suggested that a sufficiently unsteady flow might delay the onset of the Coanda effect.

\section{Pressure drop at the vocal folds}

In this section we focus on the perturbations induced on the pressure field through the static vocal-fold replica. An example of results for $L_{\mathrm{ventricle}}=26 \mathrm{~mm}$ and $h_{\mathrm{vof}}=2.90 \mathrm{~mm}$ is presented in Fig. 9. In this example $h_{\text {venf }} / h_{\text {vof }}$ is parametrically varied from 0.02 up to 1.95 by changing the ventricular-fold aperture $h_{\mathrm{venf}}$ by steps of 0.03 . For larger values of $h_{\text {venf }} / h_{\text {vof }}$, a larger step, 0.3, is used. The alimentation pressure $P_{0}$ is maintained constant as $500 \mathrm{~Pa}$. For each geometrical configuration $h_{\mathrm{venf}} / h_{\mathrm{vof}}$, pressure recordings have been repeated twice.

As shown in Fig. 9, the pressure $P_{2}$ decreases with

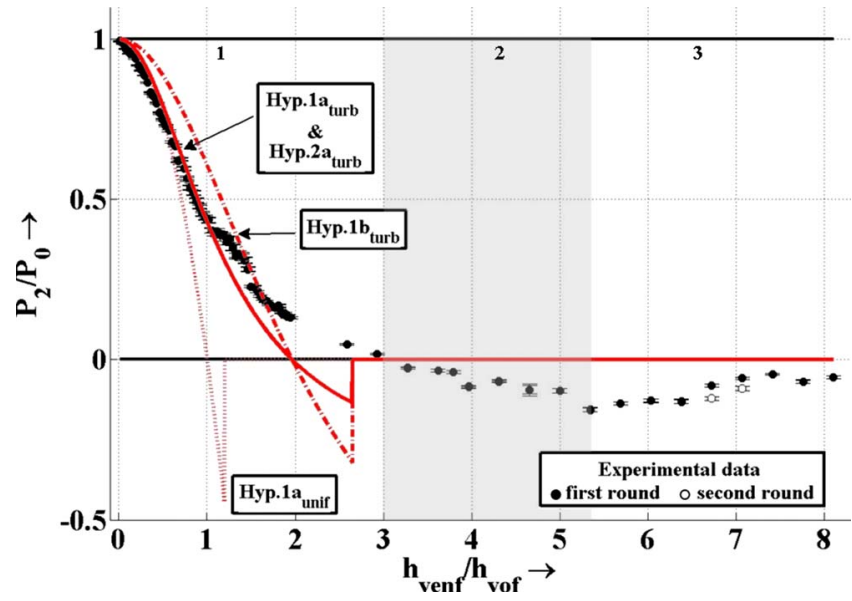

FIG. 9. (Color online) Normalized pressure recovery $P_{2} / P_{0}$ measured for two experimental rounds using the static laryngeal replica, displayed as functions of $h_{\text {venf }} / h_{\text {vof }}$ and plotted against theoretical predictions. $L_{\text {ventricle }}$ $=26 \mathrm{~mm}, h_{\mathrm{vof}}=2.90 \mathrm{~mm}$, and $P_{0 \max }=500 \mathrm{~Pa}$. Error bars correspond to the standard deviation of the measured data.

$h_{\mathrm{venf}} / h_{\mathrm{vof}}$. More precisely, different trends can be distinguished with regard to the generated perturbation on the pressure distribution (areas labelled $\{1,2,3\}$ in Fig. 9):

- For $h_{\text {venf }} / h_{\text {vof }}$ in the range from $\sim 0$ up to $\sim 3$ (area 1 ), a positive pressure $P_{2}$ is measured, reaching a $P_{0}$ value for very small values of $h_{\text {venf }} / h_{\text {vof }}$. As a consequence, the pressure drop at the vocal folds decreases down to zero when $h_{\text {venf }} / h_{\text {vof }}$ tends toward 0 .

- For $h_{\mathrm{venf}} / h_{\mathrm{vof}}$ in the range from $\sim 3$ up to $\sim 5$ (area 2), the pressure $P_{2}$ becomes negative. In this range, $P_{2}$ still decreases with $h_{\text {venf }} / h_{\text {vof }}$ down to a minimum at $h_{\text {venf }} / h_{\text {vof }}$ $\sim 5.3$. This result is in line with previous experimental observations but with different quantitative values [the minimum is reported at $h_{\mathrm{venf}} / h_{\mathrm{vof}} \sim 2$ for Agarwal (2004)].

- For $h_{\text {venf }} / h_{\text {vof }}$ higher than $\sim 5$ (area 3), the pressure $P_{2}$ is still negative but increases with $h_{\mathrm{venf}} / h_{\mathrm{vof}}$.

Two asymptotic limits $P_{2} / P_{0}=1$ (i.e., $\Delta P_{\text {vof }}+\Delta P_{\text {jet }}=0$ ) and $P_{2} / P_{0}=0$ (i.e., $\Delta P_{\text {vof }}+\Delta P_{\text {jet }}=P_{0}$ ) illustrate the physical extent of the pressure recovery qualitatively expected for very high and very low degrees of ventricular constriction, respectively. Four theoretical predictions are plotted in Fig. 9 against the experimental observations. Three of them consider a turbulent jet assumption (Hyp. $1 \mathrm{a}_{\text {turb }}$, Hyp. $2 \mathrm{a}_{\text {turb }}$, and Hyp. $\left.1 b_{\text {turb }}\right)$, while the fourth relies on a uniform jet assumption (Hyp. $1 \mathrm{a}_{\text {unif }}$ ).

The $P_{2} / P_{0}$ decrease with increased $h_{\text {venf }} / h_{\text {vof }}$ is qualitatively well predicted by the four predictions. However, an abrupt transition to $P_{2} / P_{0}=0$ is predicted by all theories as soon as $h_{\text {venf }} \geqslant h_{3}{ }^{0}$, as described in Eq. (6).

From a quantitative point of view, the theoretical prediction based on the (Hyp. $\left.1 \mathrm{a}_{\text {unif }}\right)$ assumption provides the worst estimation except for extreme values of $h_{\mathrm{venf}} / h_{\mathrm{vof}}$. Considering an empirical quasistationary pressure recovery in addition (Hyp. $1 b_{\text {turb }}$ ), like the one suggested by Ishizaka and Flanagan (1972) although providing a better estimate on average, does obviously overestimate the pressure recovery past the glottis. For very small values of $h_{\text {venf }} / h_{\text {vof }}$, the estimation of $P_{2} / P_{0}$ is even worse than the uniform jet assump- 


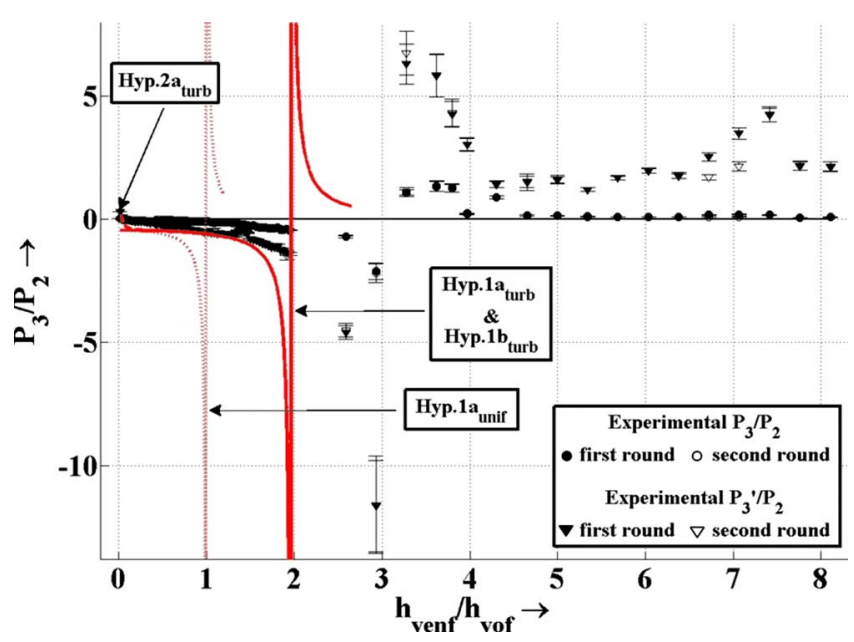

FIG. 10. (Color online) Normalized pressure ratios $P_{3} / P_{2}$ and $P_{3}{ }^{\prime} / P_{2}$ measured for two experimental rounds using the static laryngeal replica, displayed as functions of $h_{\text {venf }} / h_{\text {vof }}$ and plotted against theoretical predictions. $L_{\mathrm{ventricle}}=26 \mathrm{~mm}, h_{\mathrm{vof}}=2.90 \mathrm{~mm}$, and $P_{0 \max }=500 \mathrm{~Pa}$. Error bars correspond to the standard deviation of the measured data.

tion (Hyp. $\left.1 \mathrm{a}_{\text {unif }}\right)$. Lastly, the theoretical prediction based on the turbulent jet assumption (Hyp. $1 \mathrm{a}_{\text {turb }}$ ) provides the best estimation for the experimental data. A relative error below $8 \%$ is observed for configurations such as $h_{\mathrm{venf}} / h_{\mathrm{vof}}<1$. Therefore, this turbulent jet geometrical assumption seems more suitable for this study. Taking viscous pressure losses (Hyp. $2 \mathrm{a}_{\text {turb }}$ ) into account has very little effect and does not improve the accuracy of the predictions.

\section{Pressure drop at the ventricular folds}

In addition to $P_{2} / P_{0}$, the pressure at the ventricular folds is quantified here using ratios $P_{3} / P_{2}$ and $P_{3}{ }^{\prime} / P_{2}$. These parameters are of importance as indicators of possible ventricular-fold self-sustained oscillations.

Figure 10 displays experimental ratios $P_{3} / P_{2}$ and $P_{3}{ }^{\prime} / P_{2}$ as functions of $h_{\text {venf }} / h_{\text {vof. }}$. Two areas are exhibited:

- For $h_{\mathrm{venf}} / h_{\mathrm{vof}}$ up to $\sim 3$, the experimental data show negative pressures measured for both $P_{3}$ and $P_{3}{ }^{\prime}$, confirming a Bernoulli effect, except for two data points close to the ventricular-fold replica full adduction $\left(h_{\mathrm{venf}} / h_{\mathrm{vof}}=0.02\right.$ and $h_{\text {venf }} / h_{\text {vof }}=0.05$ ), as enhanced in Fig. 11. It is also interest-

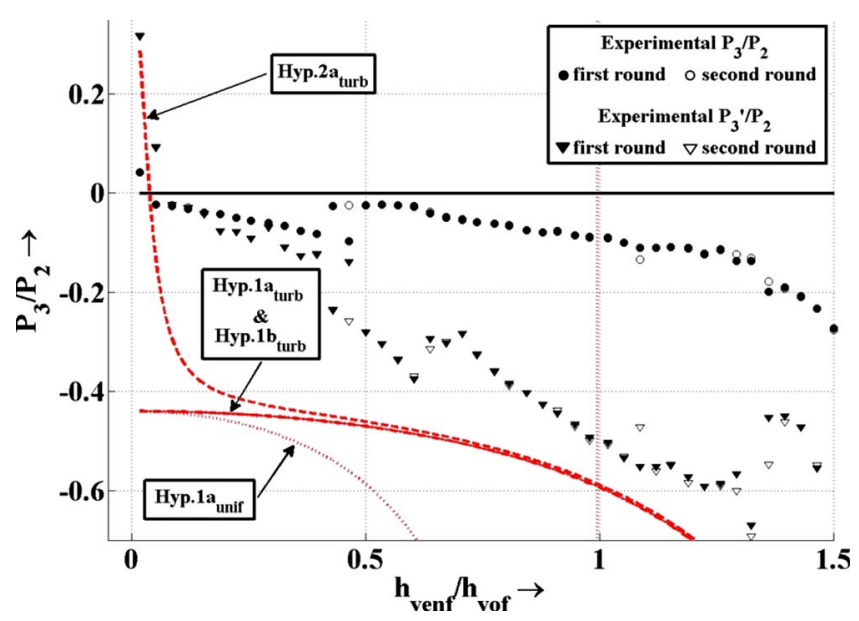

FIG. 11. (Color online) Close-up of Fig. 10.

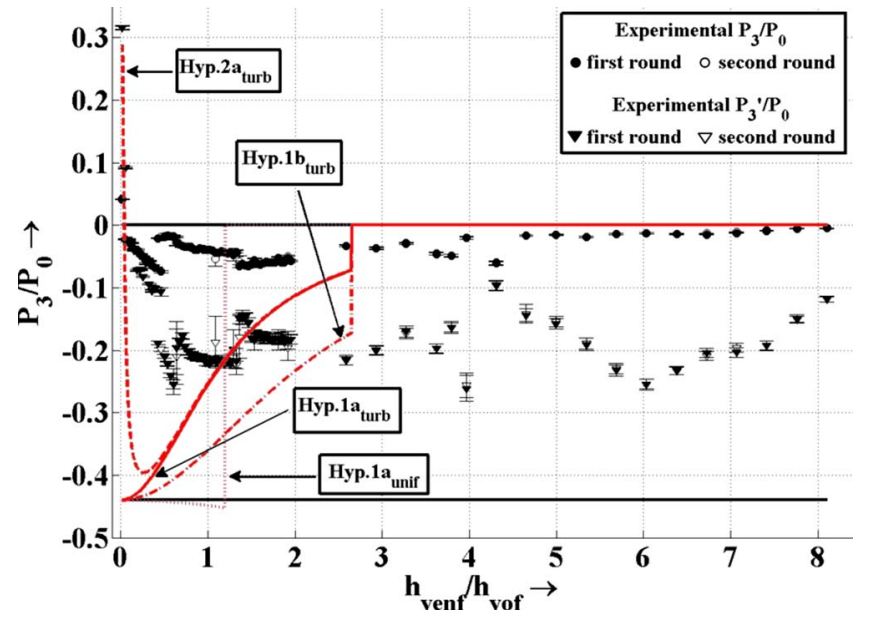

FIG. 12. (Color online) Normalized pressure ratios $P_{3} / P_{0}$ and $P_{3}{ }^{\prime} / P_{0}$ measured for two experimental rounds using the static laryngeal replica, displayed as functions of $h_{\text {venf }} / h_{\text {vof }}$ and plotted against theoretical predictions. $L_{\mathrm{ventricle}}=26 \mathrm{~mm}, h_{\mathrm{vof}}=2.90 \mathrm{~mm}$, and $P_{0 \max }=500 \mathrm{~Pa}$. Error bars correspond to the standard deviation of the measured data.

ing to note in Fig. 11 that for very small geometrical configurations such as $h_{\text {venf }} / h_{\text {vof }}<0.5, P_{3} / P_{2}$ and $P_{3}{ }^{\prime} / P_{2}$ are close. Kucinschi et al. (2006) similarly showed that a narrow geometrical configuration tends to straighten out the jet downstream to the vocal folds. As $h_{\text {venf }} / h_{\text {vof }}$ increases, the difference between $P_{3}$ and $P_{3}{ }^{\prime}$ increases and even exceeds $100 \%$ for large values. Such a case is likely to be due to a fully established Coanda effect.

- For $h_{\mathrm{venf}} / h_{\mathrm{vof}}$ exceeding 3, positive values of $P_{3} / P_{2}$ and $P_{3}{ }^{\prime} / P_{2}$ are measured. It must be noted that the scattering of measured values increases significantly, probably revealing a fully turbulent behavior of the flow.

Other illustrative parameters, $P_{3} / P_{0}$ and $P_{3}{ }^{\prime} / P_{0}$, as functions of $h_{\text {venf }} / h_{\text {vof }}$ are displayed in Fig. 12. It is shown that little of the alimentation pressure is effectively recovered (15\% on average). The four theoretical predictions are also presented on Figs. 10-12. Note that the prediction of $P_{3} / P_{2}$ is plotted until the configuration for which $P_{2}=0$. Qualitatively, the decrease in $P_{3} / P_{2}$, as well as the drastic change in sign past a critical value of $h_{\mathrm{venf}} / h_{\mathrm{vof}}$, is well predicted. Considering an additional pressure recovery (Hyp. $2 \mathrm{~b}_{\text {turb }}$ ) due to the jet reattachment has very little influence on the estimation of $P_{3} / P_{2}$. As a matter of fact, the predictions based on assumptions Hyp. $1 \mathrm{a}_{\text {turb }}$ and Hyp. $1 \mathrm{~b}_{\text {turb }}$ are identical. As shown on Figs. 11 and 12, taking into account viscosity effects in the flow (Hyp. 2a $\mathrm{a}_{\text {turb }}$ ) yields a positive prediction of $P_{3}$ for extremely small values of $h_{\text {venf }} / h_{\text {vof }}$, in line with experimental observations.

Despite these similar qualitative trends, quantitative departures with the measurement are observed for all theories. These huge discrepancies are likely to be due to the presence of a fully turbulent flow behavior, which is not accounted for by any of the predictions presented here. As a matter of fact, contrarily to $P_{2}$, the sensor heads measuring $P_{3}$ and $P_{3}{ }^{\prime}$ are located at a distance exceeding ten glottal diameters. Such a distance corresponds usually to a fully developed turbulent jet (e.g., Goldstein, 1976). 

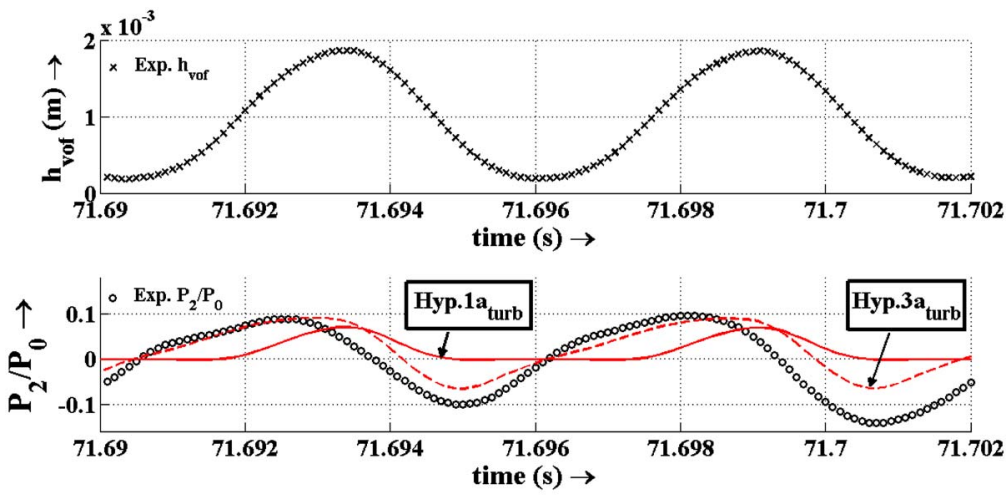

FIG. 13. (Color online) Measured data of $h_{\text {vof }}$ and $P_{2}$, $P_{3}$, and $P_{3}{ }^{\prime}$ normalized by the alimentation pressure $P_{0}$ as functions of time using the dynamical vocal-fold replica with respect to simulations with different jet assumptions. $L_{\text {ventricle }}=26 \mathrm{~mm}, h_{\text {venf }}=3.50 \mathrm{~mm}$, and $h_{\text {vof }}$ $=0.95 \mathrm{~mm}$ at rest and $h_{\mathrm{vof}}=0.97 \mathrm{~mm}$ on the average at the equilibrium position.

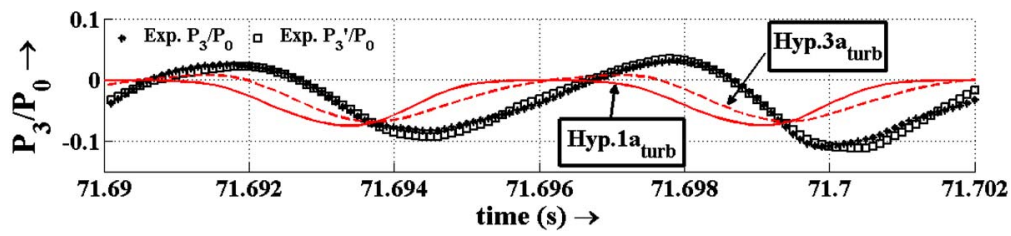

\section{B. Dynamical laryngeal replica}

\section{Influence of the constriction on the pressure distribution}

As an illustrative example, we present results obtained for $h_{\text {venf }}=3.5 \mathrm{~mm}$. The glottal replica aperture at rest was $0.95 \mathrm{~mm}$. The constant alimentation pressure is chosen as $P_{0}=1150 \mathrm{~Pa}$. For such a configuration, the latex replica is subject to self-sustained oscillations at a frequency of $176 \mathrm{~Hz}$. Typically, during an oscillation period the ratio $h_{\text {venf }} / h_{\text {vof }}$ could vary between 1.8 and 20 .

Figure 13 illustrates the pressure modulations generated by the vocal-fold self-sustained oscillations. Unsteady effects are clearly evidenced, particularly by the important phase difference between $h_{\text {vof }}$ and $P_{2}$ and between $P_{2}$ and $P_{3}$. It is interesting to note that both $P_{3}$ and $P_{3}{ }^{\prime}$ have very close values. Thus, during the dynamic experiments, the potential jet asymmetry seems to have much less effects than what was observed during the static experiments (see Sec. IV A 1). This result is in line with previous unsteady flow experiments (Pelorson et al., 1994).

Consistent with the static experiments, the experimental data show that the measured pressures $P_{2}, P_{3}$, and $P_{3}{ }^{\prime}$ are alternatively positive or negative. Negative values for $P_{3}$ and $P_{3}{ }^{\prime}$ are likely to correspond to a Bernoulli effect on the ventricular-fold replica.

For the sake of clarity, only two theoretical predictions are presented here. The first one, based on the assumption (Hyp. $1 \mathrm{a}_{\text {turb }}$ ), is considered because of its performance during the static experiments. To this latter prediction, unsteady effects have been added, which correspond to assumption (Hyp. $\left.3 \mathrm{a}_{\text {turb }}\right)$. Note that the uniform jet assumption (Hyp. $1 \mathrm{a}_{\text {unif }}$ ) would, in such a configuration, always predict a zero pressure for both $P_{2}$ and $P_{3}$ since $h_{\text {venf }}$ is always larger than the jet width $h_{s 1}$.

Considering the prediction of $P_{2}$, the turbulent jet theory in quasisteady formulation (Hyp. $1 \mathrm{a}_{\mathrm{turb}}$ ) provides a poor agreement with the measured data. Important amplitude discrepancies (of order of 60\%) are observed as well as phase differences (of order of $60^{\circ}$ ). In comparison, the turbulent jet assumption, which accounts for unsteadiness (Hyp. $3 \mathrm{a}_{\text {turb }}$ ), provides a much better amplitude prediction (of order of $20 \%$ ). Yet, although quite smaller, a phase lag is still observed (of order of $30^{\circ}$ ).

Considering the prediction of $P_{3}$, none of the theoretical predictions can explain quantitatively the measured data. Obviously, in this case, the turbulent viscous dissipation and unsteady phenomena within the jet are not correctly taken into account in the theories tested in this part. The amplitude error may be also related to the crude approximation of the glottal replica cross-sectional area, which has a more complex shape than a rectangular one.

\section{Influence of the constriction on the vocal-fold self- oscillations}

Lastly, we consider two parameters. Figure 14 presents the experimental oscillation threshold pressures $P_{\text {threshold }}$ (namely, $P_{\text {onset }}$ and $P_{\text {offset }}$ ) and fundamental frequencies $F_{0}$ averaged on two series of measurements. $h_{\text {venf }}$ ranges from 0.04 to $22 \mathrm{~mm}$. $h_{\text {vof_eq }}$ is defined as the equilibrium position,

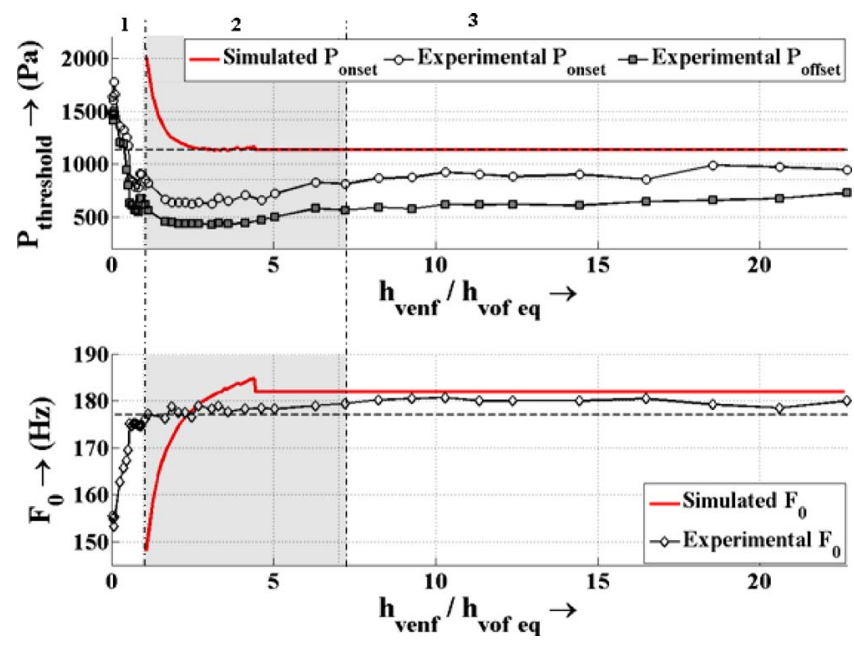

FIG. 14. (Color online) Measured threshold pressures and fundamental oscillation frequencies with corresponding two-mass model simulations, displayed as functions of $h_{\text {venf }} / h_{\text {vof eq }}$ for $L_{\text {ventricle }}=26 \mathrm{~mm}$. Experimental baselines $P_{\text {onset }}=1136 \mathrm{~Pa}$ and $F_{0}=177 \mathrm{~Hz}$ measured in a configuration without ventricular-fold replica attached are plotted in dashed lines. 
namely, the mean value of $h_{\text {vof }}$ during vocal-fold oscillations. $h_{\text {vof_eq }}$ experimental value is averaged for all $h_{\text {venf }}$ apertures allowing the optical detection of $h_{\text {vof }}$ and equals $0.97 \mathrm{~mm}$. For reference the onset pressure, offset pressure, and fundamental frequency measured without any ventricular-fold replica (i.e., for $h_{\mathrm{venf}}=h_{\text {ventricle }}$ ) are, respectively, $1136 \mathrm{~Pa}$, $833 \mathrm{~Pa}$, and $177 \mathrm{~Hz}$.

Some interesting trends can be observed. Firstly, for all the geometrical configurations explored here, experimental phonation offset pressures are found to be lower than experimental phonation onset pressures, which is in line with the hysteretic behavior noted by Lucero (1999) and Ruty et al. (2007).

Secondly, the experimental results concerning the influence of the geometrical configuration $h_{\text {venf }} / h_{\text {vof_eq }}$ can be divided into three trends, referring to three different areas labeled in Fig. 14:

- For $h_{\text {venf }} / h_{\text {vof_eq }}$ ranging up to 1 (area 1$)$, the onset pressure is found greater or comparable to the threshold pressure obtained without the ventricular-fold replica attached. This implies that a severe constriction of the ventricular folds, relative to the glottal width, impedes the vocal-fold replica vibration. Note that this behavior co-occurs with an increase of the fundamental frequency with $h_{\mathrm{venf}} / h_{\mathrm{vof} \text { eq }}$.

- For $h_{\text {venf }} / h_{\text {vof_eq }}$ ranging between 1 and 7 (area 2), the onset pressure is found to be significantly lower than the one measured without ventricular-fold replica. These results suggest that within this geometrical range, the presence of ventricular-fold replica favors the vocal-fold replica oscillations. Such an effect has been reported by Agarwal (2004), suggesting that the ventricular folds may facilitate the phonation by increasing the airflow through the larynx. The fundamental frequency remains almost constant in this area.

- For $h_{\text {venf }} / h_{\text {vof_eq }}$ higher than 7 (area 3), the onset pressure remains almost constant. The fundamental frequency is not altered by the geometrical configuration either.

The experimental results are compared to theoretical predictions using the vocal-fold two-mass model described in Sec. III C 2. The mechanical parameters of the simulation are obtained in order to fit the onset pressure and fundamental frequency measured without any ventricular folds attached. Namely, the parameters were

$$
\begin{aligned}
& m=1.90 \times 10^{-4} \mathrm{~kg}, \\
& k=2.33 \times 10^{2} \mathrm{~N} \mathrm{~m}^{-1}, \\
& k_{c}=1.16 \times 10^{2} \mathrm{~N} \mathrm{~m}^{-1}, \\
& r=6.79 \times 10^{-3} \mathrm{~N} \mathrm{~s} \mathrm{~m}^{-1} .
\end{aligned}
$$

All other parameters (alimentation pressure, initial glottal area, and geometry) were directly taken similar to those of the experiments. First, for all experimental cases the twomass model predicted self-sustained oscillations except for $h_{\text {venf }} / h_{\text {vof_eq }}<1$ where no oscillations were possible. A qualitative decrease in the phonation onset pressures is predicted by the two-mass model, however, for a smaller range (i.e., $h_{\text {venf }} / h_{\text {vof_eq }}$ between 1 and 4 instead of between 0.04 and 4 experimentally). For $h_{\text {venf }} / h_{\text {vof_eq }}>4$, the phonation onset pressures are predicted constant and equals the configuration without the ventricular folds. The fundamental-frequency increase with $h_{\text {venf }} / h_{\text {vof_eq }}$ is quantitatively well simulated.

\section{CONCLUSIONS}

The aim of this both experimental and theoretical study was to evaluate the potential influence of a ventricular constriction during voicing. Several theoretical predictions based on different flow assumptions have been proposed and tested against an in vitro experimental setup under steady or unsteady flow conditions.

The conclusions that can be drawn from this study are as follows:

- Experimentally, very different results are obtained when considering either a static or a dynamical device for the vocal folds. This is observed as the occurrence not only of unsteady effects such as the phase shift between the glottal aperture and the pressure signals but also of the stability of the jet flow. Asymmetrical flows, such as the Coanda effect, which are typically observed for steady flow conditions (Pelorson et al., 1994, 1995; Hirschberg et al., 1996; Hofmans, 1998; Hofmans et al., 2003; Scherer et al., 2001; Shinwari et al., 2003; Kucinschi et al., 2006), seem quite limited under unsteady flow conditions created by a dynamical vocal-fold replica. While asymmetrical flow might indeed occur during phonation, for example, due to some asymmetries in the vocal-fold geometry, the relevance of the Coanda effect in phonation seems therefore doubtful.

- The geometrical configuration is shown to be a critical parameter, thereby confirming earlier studies (Agarwal, 2004; Kucinschi et al., 2006). It is found that under a certain configuration, the presence of the ventricular folds can favor the oscillations of the vocal folds. On the other hand, with respect to the vocal-fold aperture, very narrow ventricular folds tend to perturbate or even suppress the vocalfold vibrations. This is due to a significant pressure recovery that occurs past the glottal channel and which therefore reduces the transglottal pressure drop. Such geometrical configurations occur when the ventricular-fold aperture are smaller or equal to the glottal aperture. In such a case, a fundamental-frequency increase with $h_{\text {venf }} / h_{\text {vof }}$ is observed. Although such a configuration is not expected in normal speech, it might be relevant during Asian vocal productions or Sardinian A Tenore singing where even a total closure of the ventricular folds is observed (Fuks et al., 1998; Sakakibara et al., 2004; Bailly et al., 2007). Some pathological cases might also be concerned by such behavior. These trends have been observed experimentally. Two-mass model simulations combined to the theoretical flow description of the ventricular-fold influence demonstrate that these trends are mainly related to aerodynamic effects.

- Whether or not the ventricular folds can self-oscillate is still unclear. While the ventricular folds are a priori poor biomechanical vibrators (Agarwal, 2004), jet reattachment 
and Bernoulli effect are indeed observed on the ventricular-fold replica. The pressure drop at the ventricular folds, which can be in first approximation estimated by $P_{2}$, can reach a considerable proportion of the alimentation pressure (e.g., $70 \%$ at $\left.h_{\mathrm{venf}} / h_{\mathrm{vof}}=0.5\right)$. This latter point has, of course, to be more extensively studied for a larger range of plausible laryngeal configurations. In particular, an in vitro experimental investigation including a deformable ventricular-fold replica, and thus capable of self-sustained oscillations, is currently under study.

- Theoretically, the prediction of all the above aerodynamical effects for the purpose of synthesis, for example, remains quite difficult. More precisely, it was shown that a simple Bernoulli theory based on the assumptions of an empirical flow separation, a linear growth of the glottal jet width, and unsteady flow effects provides a reasonable estimation of transglottal pressure drop. The glottal jet geometrical expansion appears then to be the most critical parameter. Due to the cascade of successive assumptions, the prediction of the pressure downstream remains only qualitative. At the level of the ventricular constriction, all theoretical predictions fail to explain the measured steady or unsteady data. Most probably, the high viscous dissipation within the turbulent jet has to be taken into account for such flows.

\section{ACKNOWLEDGMENTS}

This research has been supported by a Ph.D. Grant from the French Ministry of Research and Education. The authors gratefully acknowledge Pierre Chardon and Didier Blanc for their valuable contributions to the elaboration of the setup. They would like also to thank Joël Gilbert, Annemie Van Hirtum, Julien Cisonni, and Claire Brutel-Vuilmet for their participation and suggestions on this work.

Agarwal, M. (2004). "The false vocal folds and their effect on translaryngeal airflow resistance," Ph.D. thesis, Bowling Green State University, OH.

Agarwal, M., Scherer, R. C., and Hollien, H. (2003). "The false vocal folds: Shape and size in frontal view during phonation based on laminagraphic tracings," J. Voice 17, 97-113.

Bailly, L., Henrich, N., Webb, M., Müller, F., Licht, A. K., and Hess, M. (2007). "Exploration of vocal-folds and ventricular-bands interaction in singing using high-speed cinematography and electroglottography," in Proceedings of the 19th International Congress on Acoustics, Madrid, Spain.

Bailly, L., Ruty, N., Van Hirtum, A., Cisonni, J., Pelorson, X., and Henrich, N. (2006). "Aerodynamic interaction between the vocal folds and the ventricular bands," in Proceedings of the Seventh Advances in Quantitative Laryngology, Voice and Speech Research, Gröningen, The Netherlands.

Blevins, R. D. (1992). Applied Fluid Dynamics Handbook (Krieger, Malabar, FL), pp. 71-80.

Erath, B. D., and Plesniak, M. W. (2006). "The occurrence of the Coanda effect in pulsatile flow through static models of the human vocal folds," J. Acoust. Soc. Am. 120, 1000-1011.

Fuks, L., Hammarberg, B., and Sundberg, J. (1998). “A self-sustained vocalventricular phonation mode: Acoustical, aerodynamic and glottographic evidences," KTH TMH-QPSR 3, 49-59.

Goldstein, M. (1976). Aeroacoustics (McGraw-Hill, New York).

Henrich, N. (2006). "Mirroring the voice from Garcia to the present day: Some insights into singing voice registers," Logoped. Phoniatr. Vocol. 31, 3-14.

Henrich, N., d'Alessandro, C., Castellengo, M., and Doval, B. (2004). "On the use of the derivative of electroglottographic signals for characterization of nonpathological phonation," J. Acoust. Soc. Am. 115, 1321-1332.

Henrich, N., Lortat-Jacob, B., Castellengo, M., Bailly, L., and Pelorson, X.
(2006). "Period-doubling occurrences in singing: The 'bassu' case in traditional Sardinian 'A Tenore' singing," in Proceedings of the Fifth International Conference Voice Physiology and Biomechanics, University of Tokyo, Japan, July.

Hirano, M., Matsuo, K., Kakita, Y., Kawasaki, H., and Kurita, S. (1983). "Vibratory behavior versus the structure of the vocal fold," in Vocal Fold Physiology: Biomechanics, Acoustics and Phonatory Control, Denver, edited by I. R. Titze and R. C. Scherer, pp. 26-40.

Hirschberg, A., Pelorson, X., Hofmans, G. C. J., Van Hassel, R. R., and Wijnands, A. P. J. (1996). "Starting transient of the flow through an invitro model of the vocal folds," in Vocal Fold Physiology: Controlling Complexity and Chaos, edited by P. J. Davis and N. H. Fletcher (Singular, San Diego), pp. 31-46.

Hofmans, G. C. J. (1998). "Vortex sounds in confined flows," Ph.D. thesis, Technische Universiteit Eindhoven, Eindhoven, The Netherlands.

Hofmans, G. C. J., Groot, G., Ranucci, M., Graziani, G., and Hirschberg, A. (2003). "Unsteady flow through in-vitro models of the glottis," J. Acoust. Soc. Am. 113, 1658-1675.

Hollien, H., and Colton, R. H. (1969). "Four laminagraphic studies of vocal fold thickness," Folia Phoniatr. 21, 179-198.

Imagawa, H., Sakakibara, K. I., Tayama, N., and Niimi, S. (2003). "The effect of the hypopharyngeal and supra-glottic shapes on the singing voice," in Proceedings of the Stockholm Music Acoustics Conference, Stockholm, Sweden, August.

Ishizaka, K., and Flanagan, J. L. (1972). "Synthesis of voiced sounds from a two-mass model of the vocal cords," Bell Syst. Tech. J. 51, 1233-1267.

Ishizaka, K., and Matsudaira, M. (1972). Fluid Mechanical Considerations of Vocal Cord Vibration, Speech Communications Research Laboratory, Monograph 8 (Santa Barbara, CA), pp. 12-17.

Kucinschi, B. R., Scherer, R. C., DeWitt, K. J., and Ng, T. T. M. (2006). "Flow visualization and acoustic consequences of the air moving through a static model of the human larynx," J. Biomech. Eng. 128, 380-390.

Kundu, P. K. (1990). Fluid Mechanics (Academic, San Diego).

Lindestad, P. A., Sodersten, M., Merker, B., and Granqvist, S. (2001). "Voice source characteristics in Mongolian 'throat singing' studied with high-speed imaging technique, acoustic spectra, and inverse filtering," J. Voice 15, 78-85.

Lous, N. J. C., Hofmans, G. C. J., Vedlhuis, R. N. J., and Hirschberg, A. (1998). "A symmetrical two-mass vocal-fold model coupled to vocal tract and trachea, with application to prosthesis design," Acta Acust. 84, 11351150 .

Lucero, J. C. (1999). "A theoretical study of the hysteresis phenomenon at vocal folds oscillation onset-offset," J. Acoust. Soc. Am. 105, 423-431.

Miller, J. A., Pereira, J. C., and Thomas, D. W. (1988). "Fluid flow through the larynx channel," J. Sound Vib. 121, 277-290.

Nasri, S., Jasleen, J., Gerratt, B. R., Sercarz, J. A., Wenokur, R., and Berke, G. S. (1996). "Ventricular dysphonia: A case of the false vocal fold mucosal travelling wave," Am. J. Otolaryngol. 17, 427-431.

Pelorson, X., Hirschberg, A., van Hassel, R. R., and Wijnands, A. P. J. (1994). "Theoretical and experimental study of quasisteady-flow separation within the glottis during phonation: Application to a modified twomass model," J. Acoust. Soc. Am. 96, 3416-3431.

Pelorson, X., Liljencrants, J., and Kroeger, B. (1995). “On the aeroacoustics of voiced sound production," in Proceedings of the 15th International Congress on Acoustics, Trondheim, Norway.

Pinho, S. M. R., Pontes, P. A. L., Gadelha, M. E. C., and Biasi, N. (1999). "Vestibular vocal fold behaviour during phonation in unilateral vocal fold paralysis," J. Voice 13, 36-42.

Roubeau, B., Henrich, N., and Castellengo, M. (2008). "Laryngeal vibratory mechanisms: The notion of vocal register revisited," J. Voice, 9 June.

Ruty, N., Pelorson, X., Van Hirtum, A., Lopez-Arteaga, I., and Hirschberg, A. (2007). "An 'in-vitro' setup to test the relevance and the accuracy of low-order vocal folds models," J. Acoust. Soc. Am. 121, 479-490.

Ruty, N., Van Hirtum, A., Pelorson, X., Hirschberg, A., and Lopez-Arteaga, I. (2006). "A preliminary study of asymmetric vocal fold vibrations: Modeling and 'in-vitro' validation," in Proceedings of the Seventh International Seminar on Speech Production, Ubatuba, Brazil.

Sakakibara, K. I., Imagawa, H., Niimi, S., and Tayama, N. (2004). "Physiological study of the supraglottal structure," in Proceedings of the International Conference on Voice Physiology and Biomechanics, Marseille, France, August.

Sakakibara, K. I., Konishi, T., Kondo, K., Murano, E. Z., Kumada, M., Imagawa, H., and Niimi, S. (2001). "Vocal fold and false vocal fold vibrations and synthesis of khoomei," in Proceedings of the International 
Computer Music Conference, Havana, Cuba, Sep., pp. 135-138.

Scherer, R. C., Shinwari, D., DeWitt, K. J., Zhang, C., Kucinschi, B. R., and Afjeh, A. A. (2001). "Intraglottal pressure profiles for a symmetric and oblique glottis with a divergence angle of 10 degrees," J. Acoust. Soc. Am. 109, 1616-1630.

Shadle, C., Barney, A., and Thomas, D. (1991). "An investigation into the acoustics and aerodynamics of the larynx," in Vocal Fold Physiology: Acoustics, Perceptual and Physiological Aspects of Voice Mechanisms, edited by J. Gauffin and B. Hammarberg (Singular Publishing Co.), pp. $73-82$.

Shinwari, D., Scherer, C., DeWitt, K. J., and Afjeh, A. A. (2003). "Flow visualization and pressure distributions in a model of the glottis with a symmetric and oblique divergent angle of 10 degrees," J. Acoust. Soc. Am. 113, 487-497.

Tsai, C., Shau, Y., and Hsiao, T. (2004). "False vocal fold surface waves during Sygyt singing: A hypothesis," in Proceedings of the International Conference on Voice Physiology and Biomechanics, Marseille, France, August.

Van Hirtum, A., Cisonni, J., Ruty, N., Pelorson, X., Lopez, I., and Van Uittert, F. (2007). "Experimental validation of some issues in lip and vocal folds physical models," Acta Acust. 93, 314-323.

Wilson, J. E. (1976). "Variations of the laryngo-pharynx in singing," The NATS Bulletin 31, 20-22.

Zhang, Z., Neubauer, J., and Berry, D. (2006). "The influence of subglottal acoustics on laboratory models of phonation," J. Acoust. Soc. Am. 120, $1558-1569$.

Zhang, C., Zhao, W., Frankel, S. H., and Mongeau, L. (2002). "Computational aeroacoustics of phonation, Part II: Effects of flow parameters and ventricular folds," J. Acoust. Soc. Am. 112, 2147-2154. 